\title{
Sustainable, durable concrete - are specifications always fit for purpose - a case study
}

\author{
Michael G. Grantham ${ }^{1 *}$ \\ ${ }^{1}$ Consultant to Sandberg LLP, London and Visiting Professor at Leeds University, UK.
}

\begin{abstract}
This paper examines the drive in the construction industry to source materials for new construction sustainably. It examines the key drivers that sustainable construction entails but also looks at the crucial impact that over-specifying can have on the performance of concrete in the field. Sustainability is, however, just one concern to the modern Engineer, and ensuring the concrete can be placed and compacted adequately is also a very real concern, especially where visual concrete is concerned. The paper examines some of the issues around sustainability and also looks at several case studies where concrete has not performed as expected and has caused very real problems in the field, when using secondary cementitious materials (SCMs) in conjunction with superplasticiser. The paper concludes with some guidance on how to achieve the best of both aims - sustainability and durability, while avoiding some of the pitfalls that can occur.
\end{abstract}

\section{Introduction}

There is a very big drive in the construction industry to take a more sustainable approach to construction so that the environmental impact of the project can be minimised. Typically, this involves reducing the Carbon Footprint of the concrete as far as possible, reusing waste materials where feasible and taking steps to minimise embodied energy and "cradle to grave" energy. The concrete centre (2011) offers the following guidance when specifying concrete to achieve the optimised balance between performance and low environmental impact;

- Do not over specify strength

- Consider the possibility of strength conformance at 56 days rather than 28 days

- Specify responsibly sourced concrete and reinforcement

- Do not specify aggregate sizes below $10 \mathrm{~mm}$ unless necessary

- Permit the use of secondary or recycled aggregates but do not over specify

- Specify that concrete should always contain CEM II/CEM III or an addition

- Embodied CO2 (eCO2) of concrete should not be considered or specified in isolation of other factors such as strength gain

- Permit the use of admixtures

- Recycled aggregate should only be specified when they are locally available, otherwise transportation impacts exceed the benefits.

- Use of embodied additions can reduce the embodied $\mathrm{CO}_{2}\left(\mathrm{eCO}_{2}\right)$ of concrete and influence its visual appearance. When aesthetics are critical, specify the cement/combination to ensure colour consistency.
- Admixtures can be used to enhance the sustainability credentials and reduce the $\mathrm{eCO}_{2}$ of concrete, as well as modifying its physical characteristics.

Sustainability in construction should not only include the carbon footprint of the structure or indeed the respective materials alone. Many authors refer to sustainability having three main areas, these being; economic, social and environmental. An holistic approach needs to be taken in these matters to ensure that the best approach is found and that it is 'sustainable' in the future.

Purnell and Black (2012) highlight various specific characteristics of concrete and the resultant effect upon the carbon footprint. These are the cement, use of admixtures specifically, superplasticisers and the use of additions in the form of PFA. They also make mention of the fact that the correct specification of strength is important and will have an impact upon the total eCO2 per $\mathrm{MPa}$ but beyond about $60 \mathrm{MPa}$ (a strength class that is not often required in construction) these benefits are eroded.

Durability concerns are another significant driver in deciding the type of concrete to be used in a project, with concern about chloride ingress and/or sulfate attack being amongst the prime considerations, especially in the Middle East. This often dictates the use of secondary cementitious materials (SCMs) such as ground granulated blastfurnace slag (GGBS) and pulverised fuel ash (PFA) and sometimes ternary blends comprising CEM1, PFA and microsilica. Such concretes will often specify large doses of superplasticiser to ensure workability and high replacement levels to minimise chloride ingress or chemical attack.

In deciding the concrete to be used in a project, clearly these concerns are of key importance, but equally, so is the need for the concrete to be homogeneous and easily

\footnotetext{
*Corresponding author: michael.grantham@sandberg.co.uk
} 


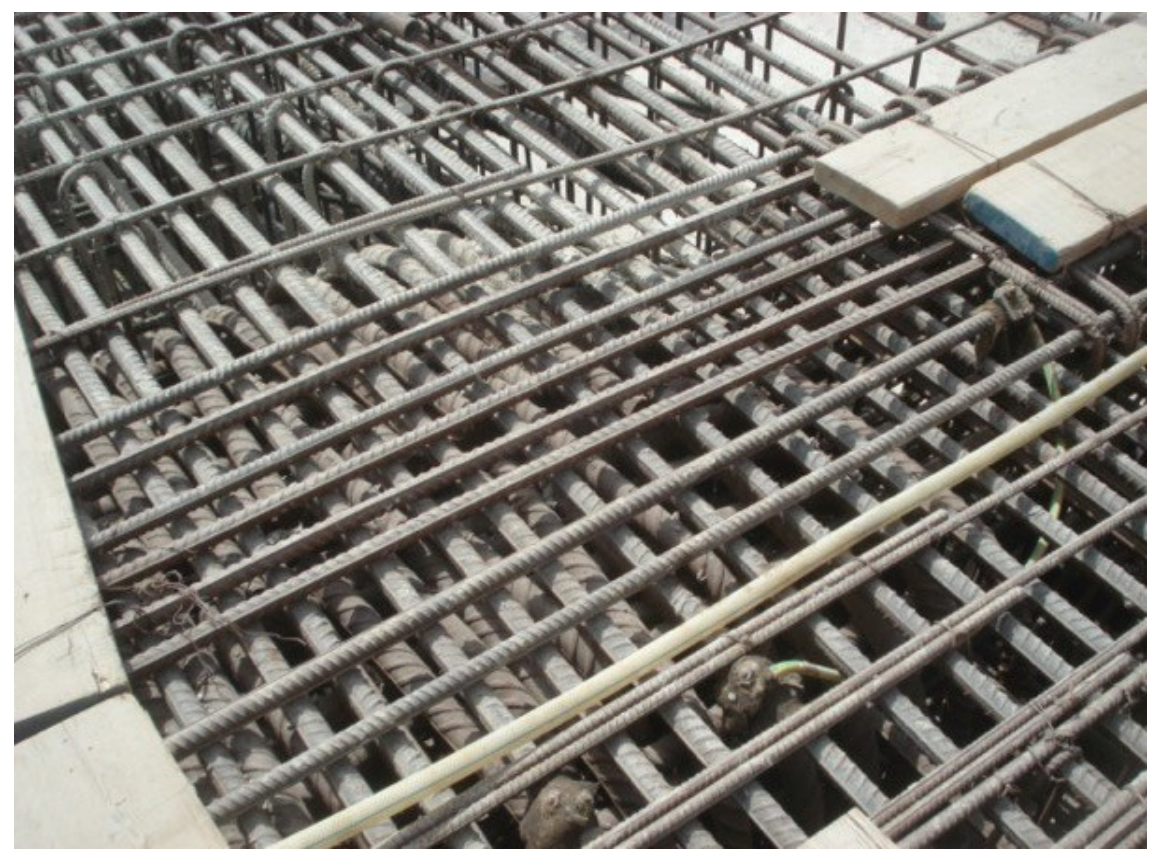

Fig. 1. Highly congested steel - designers need to consider how a contractor will ensure proper flow of concrete in such cases

placed, not to segregate and to be sufficiently workable to surround the reinforcement to provide the required level of protection to the steel reinforcement. It is no good having a highly impermeable concrete to exclude chloride if, in practice, it is so difficult to place that honeycombing results. That quite simply defeats the whole purpose of specifying for durability. Designers also need to think very carefully about buildability, when designing highly congested reinforcement into structures.

\section{Specifications}

The author was recently involved in a significant project in the Middle East where over specifying the concrete resulted in causing more problems than it solved. It is normal to give the contractor design parameters for the concrete, but then to leave the contractor to select a concrete that meets those parameters without micromanaging the specification. In the contract in question, the following design parameters were given.

To be reduced to $20 \mathrm{~mm}$ if the usage of $40 \mathrm{~mm}$ maximum aggregate is not permitted/possible due to horizontal spacing of reinforcement (2.5xmax aggregate size)

However, in addition to specifying a target chloride migration value, the specification also contained a clause where GGBS was to be used as follows

a) Blast furnace cement complying with BS EN $197-1$, CEM III/B42, $5 \mathrm{~N}$ or $52,5 \mathrm{~N}$ with min. $66-80 \%$ slag content.

In effect, this meant both a performance requirement AND a prescriptive requirement, where surely both are not necessary and meant an unduly restrictive situation for the Contractor.

The maximum w/b ratio was also to be set to a target value at least 0.02 below the specified value, effectively meaning a maximum of 0.4 .
Table 1 - Extract from Concrete Specification

\begin{tabular}{|c|c|c|c|c|c|c|}
\hline 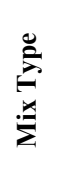 & 总 & 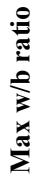 & 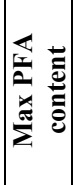 & 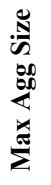 & 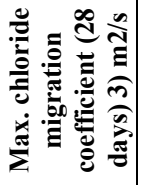 & 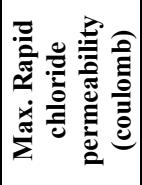 \\
\hline $\mathrm{C} 40$ & $\begin{array}{l}\text { Portland cement } \\
+ \text { fly ash }+ \\
\text { possibly silica } \\
\text { fume }\end{array}$ & $\stackrel{+}{\stackrel{+}{\circ}}$ & లి & $\stackrel{\leftrightarrow}{+}$ & 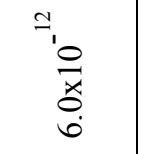 & $\stackrel{8}{\circ}$ \\
\hline & Slag cement & & - & & $\begin{array}{c}I_{1} \\
\stackrel{x}{x} \\
\stackrel{x}{0}\end{array}$ & \begin{tabular}{l}
8 \\
\hdashline \\
\hdashline
\end{tabular} \\
\hline & $\begin{array}{l}\text { Portland } \\
\text { Cement } \\
+ \text { GGBS }\end{array}$ & & & & $\begin{array}{c}\tau_{1} \\
\stackrel{0}{x} \\
\frac{x}{0}\end{array}$ & $\stackrel{8}{8}$ \\
\hline
\end{tabular}

Of the options given to the contractor, and in the light of their experience in using PFA in the region, the contractor selected the GGBS option, although not fully appreciating that the requirement for a GGBS content of $66-80 \%$ was mandatory. A ternary blend with microsilica was also considered but the microsilica was not available as a slurry and so incurred a long mixing time to disperse. The contractor wanted to use a $40 \%$ GGBS mix and showed from trials that it met the specification in all respects - adequate strength, chloride permeability, workability etc. After initially seeming to accept the 


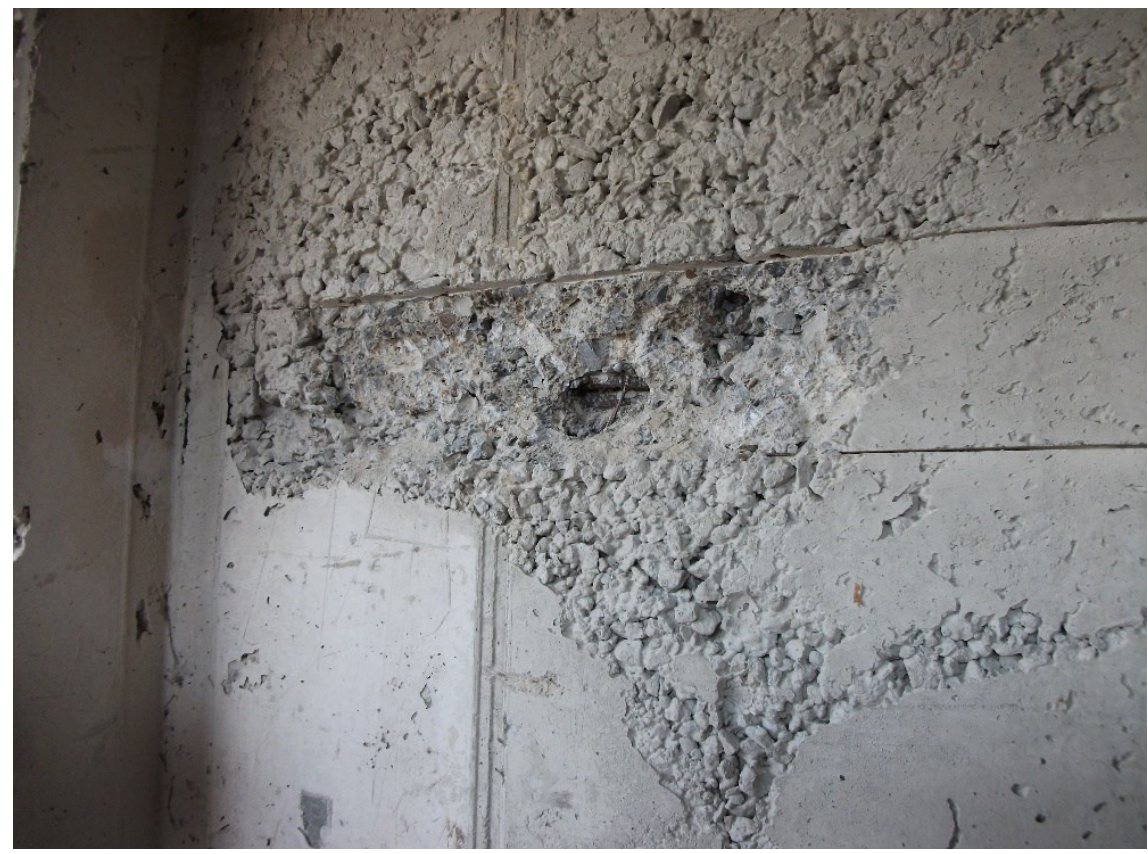

Fig. 2. Honeycombing resulting from difficulty in placing concrete with highly congested steel.

idea the Engineer finally rejected it because it did not meet the $66 \%$ minimum slag criterion.

However, if Concrete Society Technical Report CS163 (2008) is consulted it could be shown that since the structures in question were some $1.5 \mathrm{~km}$ from the sea, they did, in fact, only fall into the "Aggressive" category. This would have permitted a minimum cementitious content of $360 \mathrm{~kg} / \mathrm{m}^{3}$, a w/b ratio not exceeding 0.45 and a strength class of $\mathrm{C} 40$ (now $\mathrm{C} 32 / 40$ ) and using a CEMIIIA concrete with a slag content of 36 to $65 \%$. Therefore, rejecting the lower slag suggestion put forward by the contractor for the superstructure concrete was unjustified. This was especially so if the fact that a large proportion of the concrete was internal, clad in stone (with an underlying bituminous coating) or coated. Clearly buried parts of the structure were subject to more onerous exposure conditions and undoubtedly required a higher level of protection, but the foundations were relatively lightly reinforced so placement problems were not such an issue.

Of particular note, for internal concrete, which was all to be air conditioned, the governing durability mechanism was carbonation and not sulfate or chloride. In such circumstances, using a high level of SCM actually increases the risk of carbonation (because of the reduction in calcium hydroxide caused by the pozzolanic reaction) and is not to be recommended.

There were further complications in the case of the particular structure and region. The wadi sand in the region tended to be high in clay content and did not work well with the more modern PCE type superplasticers. This meant that the older, less capable, generation of sulphonated naphthalene type superplasticisers had to be used (Fig 3) (although an admixture manufacturer has subsequently developed an additive to overcome this problem and which allows a PCE admixture to be used with clay bearing sands. (Estephane and Rieder, 2017).

In addition, because the cement in the region was known to be of variable quality and had a reputation for periodic dips in strength, a low $\mathrm{w} / \mathrm{b}$ ratio was selected by the contractor -0.36 to ensure compliance on strength (and even maintained that following a recommendation from its own technical department to increase the water content, following the workability issues). The combination of high GGBS content, high superplasticiser content and low $\mathrm{w} / \mathrm{b}$ ratio resulted in a concrete with a tendency to thixotropic behaviour. This meant it tended to very poor workability despite meeting initial slump requirements and suffered significant slump loss. and was very difficult to place in congested reinforcement areas. The result was some significant honeycombing (Fig 2), although in practice only a very small proportion of the concrete was affected.

A further problem was also encountered which has not yet been fully researched. On this project (Fig. 4) and several in the UK, the concrete suffered from very significant segregation, with the cement paste separating from the aggregates. This caused a layer of cement rich fines at the concrete surface. Similar problems have occurred in piling concrete in the UK. Arup (unpublished) reported, at a Concrete Society meeting in London in May 2017, having found segregation in concrete piles resulting in a layer of up to several metres of fines on the top of the piles (Fig. 5). Similar experiences were apparent in comments from the audience. The common denominator appears to be the use of a high slag content with high levels of superplasticiser. 


\section{Slump vs Mix/Temp/Humidity}

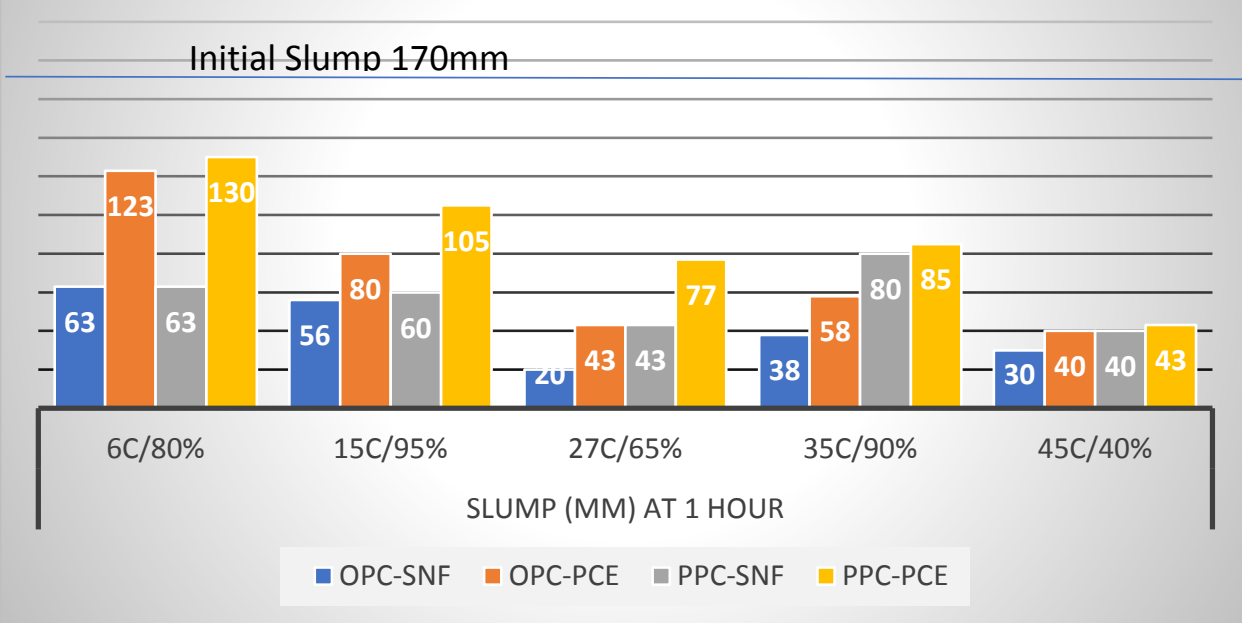

Fig. 3. Slump Loss at Different Temperatures and Humidities for PCE and SNF (From Santhanamam, 2013) - PPC $=$ Portland Pozzolana Cement

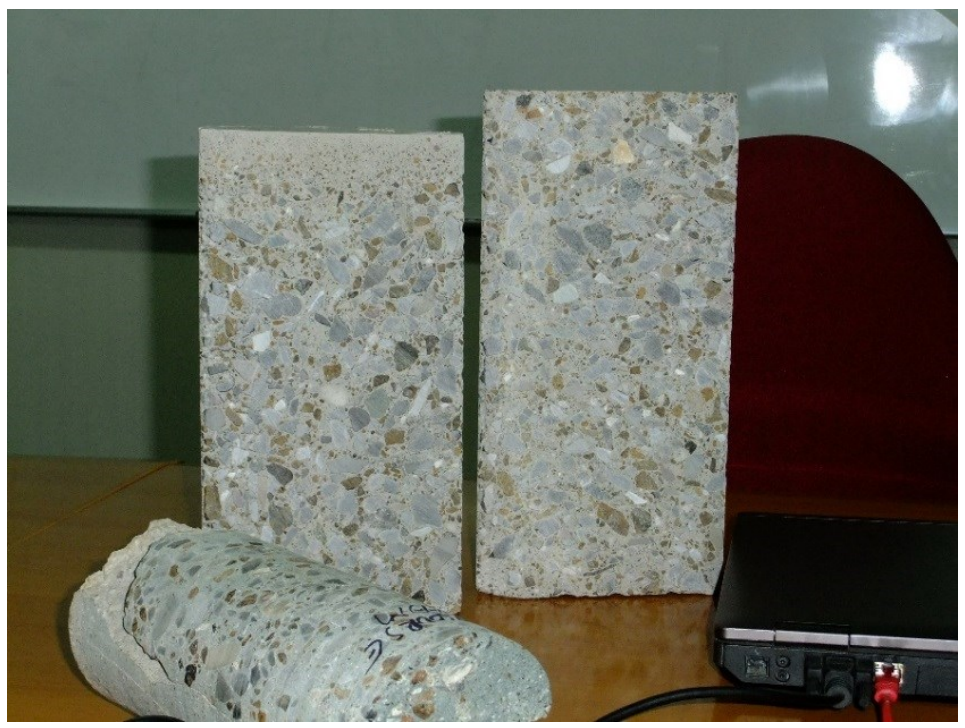

Fig. 4. Segregation in concrete from a wall showing layer of fines at the surface.

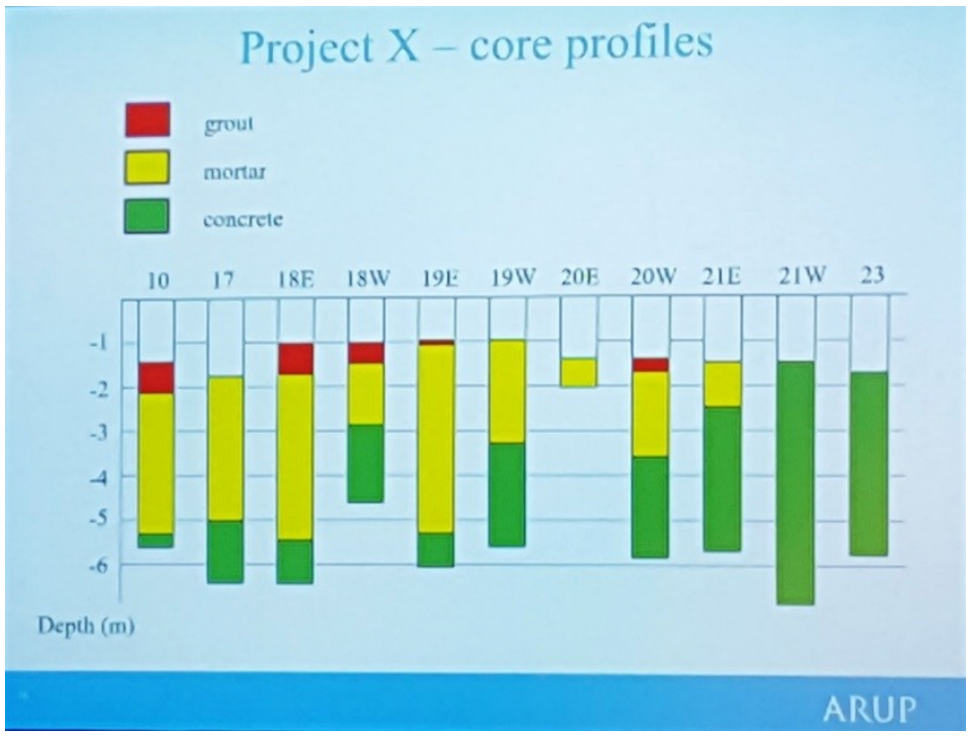

Fig. 5. Profile of concrete in piles from an unnamed project (Arup). 
In the UK, the Highways Agency (2016) have recommended a GGBS content not exceeding $50 \%$ for C32/40 concrete for paving owing to concerns about segregation and surface durability and the UK Piling Federation have introduced a stability test into specifications for piling concrete to try and identify concrete likely to suffer from the problem.

So, despite the desirability to maximize the use of $\mathrm{SCMs}$ to reduce carbon footprint and to use waste materials in the most sustainable way, wherever possible, a full consideration of the consequences of doing that are absolutely essential to ensure that the end product is fit for purpose.

\section{Practical consequences for site works}

Too often, the relationship between Engineer and Contractor can become difficult. These two parties are key to the success of a project and proactive co-operative approach between the two will mean a smooth project and a good end product!

In the Middle East project, the relationship between Contractor and Engineer became totally broken. The Engineer and Client claimed that all the concrete was defective. In fact, calculations performed using the number of bags of repair material showed that only approximately $0.2 \%$ of the concrete had been repaired (still a substantial amount of concrete given the size of the project, but by no means all of it).

Where honeycombed concrete was encountered it was always broken back behind the reinforcement whether the honeycombing extended that far or not. This happened even in the case of very shallow honeycombing. Where honeycombing was repaired, the Engineer insisted on a pull-off test to ensure adhesion of the repair - on each and every repair! - even if the repair was only $150 \mathrm{~mm}$ in size. EN1504 in Table 4 of Part 10 of the Standard (BSI, 2003) requires only that a pull off test is conducted once for each type of surface or member. Sensibly, even if the Engineer chose a more onerous regime, that could have been modified depending on the results obtained - reducing the number of tests as more satisfactory results were obtained.

The project used traditional timber formwork, with cast in plastic tubes to take tie rods. Most contracts require only that the ends of the tubes are removed and the holes filled with repair mortar. At the extreme that might extend to filling the whole tube, although that is not normal industry practice. In this project, however, the Engineer insisted that ALL of the plastic tube was removed by drilling it out (in some cases quite significant lengths of tube) and then filling the resulting hole with repair mortar. This was a task that took several hours to repair a single hole - and there were many thousands of such holes on the project. In the end, the contractor refused to comply.

In casting shear walls, the project specification required curing under polythene for 14 days. The Contractor wanted to cast the shear walls in a continuous run and then apply the required curing. The Engineer commented that while the external surfaces of the walls were therefore cured for 14 days under polythene, the ends of each wall where they butted against each other were not being cured under polythene! No amount of argument by the Contractor that the adjacent concrete would provide the required curing would shift the Engineer from their position. In the end, the Contractor had to cast the walls in a "hit and miss" fashion, with gaps between walls, walls cured under polythene (including the ends) and then finally the gaps infilled before repeating the curing. Of course, this meant that the ends of the infill walls could not be cured under polythene anyway, which was their original point!

In the case of the segregated concrete, this tended to suffer from shrinkage cracking, owing to the lack of coarse aggregate. Surprisingly, however, the segregated mortar at the surface was extremely hard and perfectly capable of performing its function once the shrinkage cracks were dealt with. The ability of the mortar was tested by compression and shear testing and in fact was shown to behave similarly to the repair material that was being used to replace it when it was cut out. Yet a considerable amount of very shallow surface removal was still done to remove areas of minor segregation.

As with many contracts, blowholes were encountered in the concrete surface, once the formwork was struck. These are a normal feature of concrete and are readily rectified by filling in with grout or repair mortar. Indeed, in a CIRIA Publication, (CIRIA, 1999) it states "Achieving blowhole-free concrete can be extremely difficult, and is not possible for vertical and sloped surfaces." Yet in this project, the Engineer insisted that all blowholes where the hole at the surface was smaller than at depth were drilled out before filling with repair material. This, in practice meant that the contractor had to cut all the holes out rather than entering into protracted arguments about whether to drill out each individual hole. This made large blemishes out of small ones and increased considerably the time and effort in making good the concrete. Indeed, it could be argued that the depth of most blowholes was within the cover tolerance and could simply have been left alone in many cases where the concrete was not going to be visual (i.e, where clad or covered).

Overall, the problems multiplied on the project, with long delays in signing off remedial work, which delayed follow on work. The contractor estimated that it added an extra year to the project and took legal action to recover the lost money, which ran into many millions of pounds. 


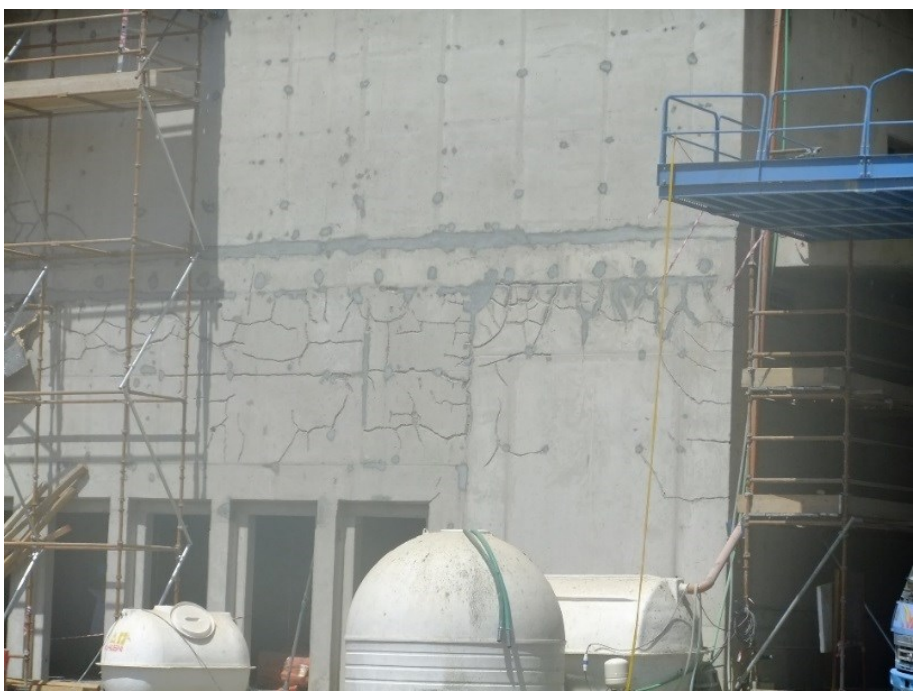

Fig. 6. Shrinkage crazing in wall where concrete segregation had occurred.

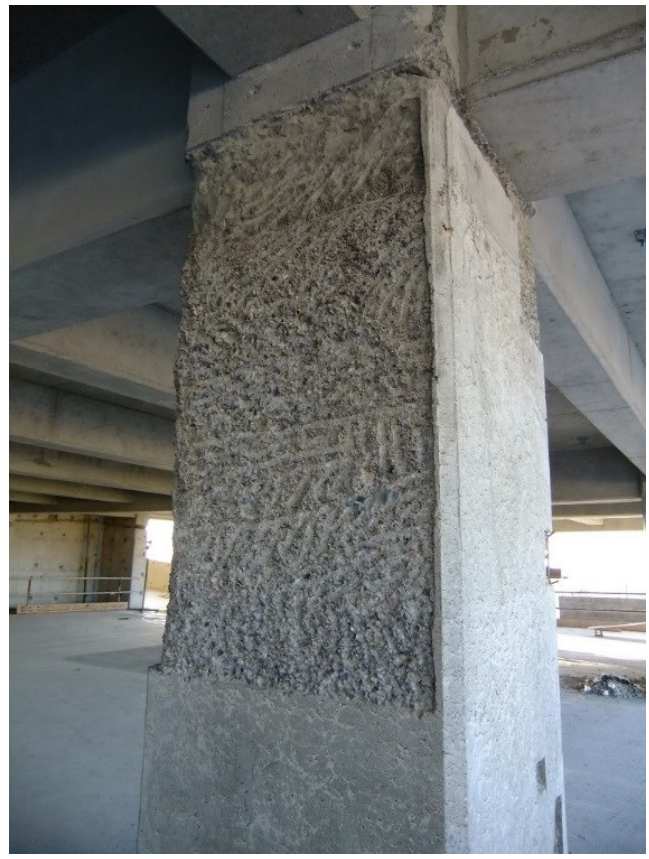

Fig. 7. Unnecessary surface removal of concrete to deal with minor shrinkage and crazing

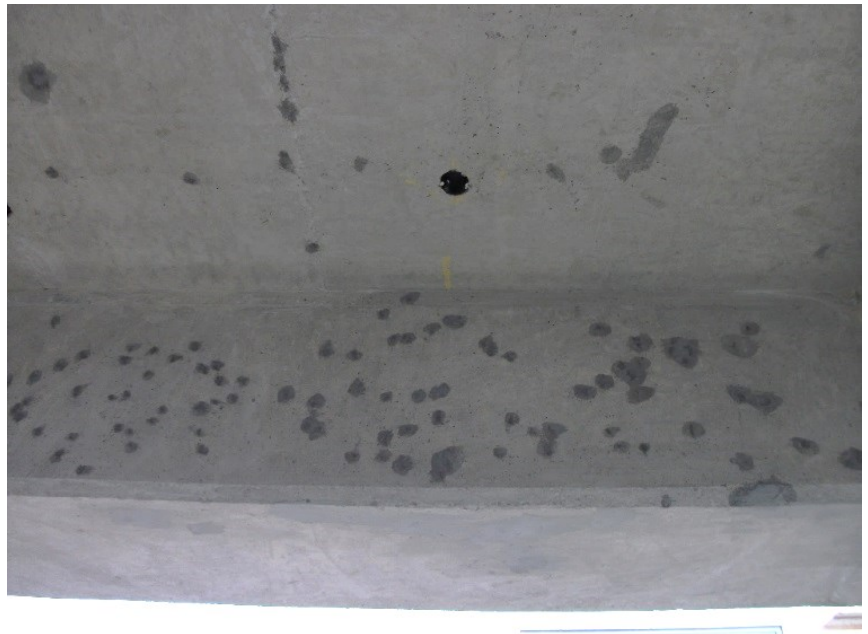

Fig. 8. Blowholes drilled out to fill with repair mortar 


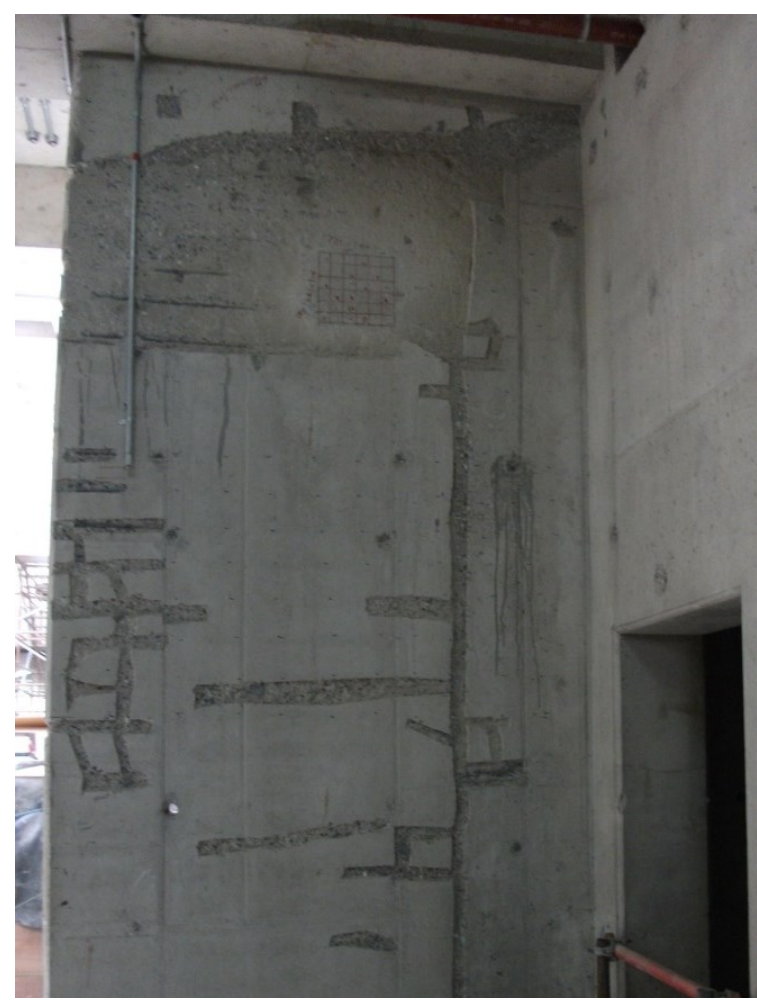

Fig 9. Minor cracks chased out prior to making good, rather than applying an elastomeric coating.

\section{Lessons to be learned}

Sustainability is clearly a desirable objective to minimise the use of virgin materials, to re-use waste materials wherever possible and to minimise the embodied carbon and energy use in materials. However, it is key to carefully consider the cost and the benefit before making decisions.

- Is it sensible to specify the use of recycled material that isn't available locally unless the environmental impact of transporting that material to site is also taken into account?

- Will the sustainable concrete perform as well or better than an equivalent concrete made using virgin materials and if not, can the performance loss be justified based on the improved sustainability?

- Does the use of CSM's or added recycled material provide a concrete that behaves sufficiently well (in terms of consistence, slump retention, cohesion and resistance to segregation) to justify its use? Could improved performance be achieved with a lower addition, even if that is not quite so "sustainable?"

- Decide on the performance you require from the concrete and specify the concrete accordingly via a performance specification. Avoid micro-managing the composition of the concrete, provided it meets the performance requirement (unless visual appearance dictates a particular concrete composition). The Contractor should have the freedom to design the best concrete for a particular job that he or she can work with and place satisfactorily.
- Think carefully about buildability of construction elements. Don't make steel reinforcement so congested that concrete cannot be placed around it!

- Do consider the use of recycled material, locally available recovered material (rice husk ash, recycled concrete aggregate (RCA) etc) if the performance of the concrete isn't compromised or in parts of the structure that don't have the same performance requirements.

- Work co-operatively as a team with input from the Designer, the Engineer, the Client and the Contractor listening to each other to make sure that the project is undertaken in the best, most cost-effective way. Taking an adversarial approach is invariably a recipe for disaster!

\section{REFERENCES}

1. BS EN 1504-10:2003 "Products and systems for the protection and repair of concrete structures. Definitions. Requirements. Quality control and evaluation of conformity. Site application of products and systems and quality control of the works" British Standards Institution, London.

2. Concrete Society Technical Report 163, "Guide to the Design of Concrete Structures in the Arabian Peninsula, 2008, The Concrete Society, UK.

3. Construction Industry Research and Information Association (CIRIA), C519 (1999): "Action in the case of nonconformity of concrete structures", at section 6.3.8.

4. Estephane, P Rieder, K.A. "Advanced analysis of an engineered solution for high permissible limits of clay in contaminated sands used in concrete." Concrete for the Modern Age, Developments in materials and processes. Proceedings of an International Conference, Military Technical College, Muscat, Oman, Now 2017. Whittles Publishing. Caithness, Scotland.

5. Highways Agency, Manual of contract documents for highway works, Volume 1 specification for highway works. Amendment Feb 2016. Accessed August 2017.

6. http://www.standardsforhighways.co.uk/ha/standar ds/mchw/vol1/pdfs/MCHW\%201000.pdf,

7. Purnell, P. and Black, L. (2012). Embodied carbon dioxide in concrete: Variation with common mix in design parameters. Cement and Concrete Research, 42 (6), 874-877

8. Santhanam, M." Evaluation of Superplasticizer Performance in Concrete" Third International Conference on Sustainable Construction Materials and Technologies 19-21 August 2013 Kyoto Research Park, Kyoto, Japan with the University of Kyoto http://www.claisse.info/Proceedings.htm, accessed August 2017

9. The Concrete Centre/MPA "Specifying Sustainable Concrete." 2011 